\title{
Characteristics of Control Piston Motion and Pressure Inside of a Common Rail Diesel Injector
}

\author{
Sebastian Schuckert*1, Georg Wachtmeister ${ }^{1}$ \\ ${ }^{1}$ Chair of Internal Combustion Engines, Technical University of Munich, Germany \\ ${ }^{*}$ Corresponding author: schuckert@Ivk.mw.tum.de, ORCID ID: 0000-0002-8668-7733
}

\begin{abstract}
In this paper the experimental setup of a commercial third generation common rail solenoid injector with advanced measurement is discussed. The motion of the control piston is measured while performing injection rate investigations using a purpose-built injection rate analyzer of the Bosch type. At the same time fuel pressure in the feed line of the nozzle is gauged and contrasted to fuel pressure before the inlet connector.

In contrast to the steady rise observed in a similar study, the motion of the control piston in this case is characterized by a changing gradient in the upward movement. The magnitude of the negative displacement of the upper part of the control piston due to the fuel pressure in the control volume corresponds to simulation results of the elastic deformation.

Pressure before the inlet connector and pressure in the feed line exhibit a similar course with a difference in magnitude that is rising with higher rail pressures. Precisely with the end of injection the pressure in the feed line surpasses the pressure before the inlet connector for a short moment. The measurement results of control piston motion and pressure inside the injector are of particular interest because these parameters are to serve as indicators for changes in the injection rate caused by phenomena like wear and coking amongst others.
\end{abstract}

\section{Keywords}

common rail injector, injection rate measurement, eddy current sensor, control piston motion, feed line pressure

\section{Introduction}

The act of injecting diesel not only supplies the fuel for the subsequent combustion, but at the same time also determines the start of combustion with the diesel combustion process. This is unlike the gasoline combustion process, where injection and ignition are separated. Thus, the injection process is a major influence factor to consider in order complying with the increasingly severe emission legislation for compression ignition engines.

Furthermore, alterations affecting the injection parameters of common rail diesel injectors that emerge during engine operation have been identified. Research efforts focused on brittle external nozzle deposits mostly consisting of carbon referred to as coking. In recent years, a type of sticky, the so-called internal diesel injector deposits (IDID) have appeared in production engines and caused needles to stick in common rail diesel injectors. It has been observed that the addition of certain additives (polyisobutylene succinimide; PIBSI) to diesel fuel, which are to inhibit the formation of coking deposits, have the side effect of contributing to the formation of IDID [1][2]. These PIBSI react with acids that emerge from fatty acid methyl ester (FAME), a biodiesel supplement to common diesel in the European Union, to form IDID. Other major factors that influence the occurrence of IDID are high fuel temperatures and the content of aromatics and oxygen in the diesel fuel [2].

Deposits on the nozzle tip and inside the nozzle holes due to coking cause numerous adverse effects. It is proven that this type of deposits exerts a great influence on the injection rate of an injector, impairs the break-up of the fuel spray and leads to an inferior mixing of fuel and air in the combustion chamber [3]. In addition, coked nozzles exhibit larger cyclic variations of cylinder peak pressure than clean nozzles, even though the visible spray pattern appears unchanged [4]. Ultimately, external deposits lead to a deterioration of combustion efficiency, a decrease in rated power and cause a rise in brake specific fuel consumption [5]. The formation of coking deposits is driven by higher temperatures at the nozzle and in its spray holes, while cavitation inside the nozzle serves as an inhibitor to their built-up [6][7]. Cavitation inside the nozzle induced by a lower discharge coefficient proved to be beneficial against coking. A positive effect also applies to high spray hole conicity due to a built-up of deposits which is predominant in the inlet region of the hole [6]. In summary, coking deposits will be a key influencing parameter for future nozzle designs [8].

Legislative constraints together with the problem of internal and external injector deposits have led to the development of systems that are to maintain optimal fuel consumption and emissions optimal over the entire engine lifetime [9][10][11][12]. These closed-loop control strategies have been presented for both light [9][12] and heavy duty engines [11]. All these principles have in common that the fuel pressure inside the injector is measured and 
evaluated applying pressure transducers to the injectors [9][11] or utilizing the piezo-actuator of the injector itself to calculate the inside pressure [12]. Algorithms are utilized to determine key injection parameters like start and end of injection as well as the maximum injection rate and quantity [10]. These injection controls enable a very high injection quantity accuracy and close timings between pilot and main injection that are favorable for reducing nitrogen oxide emissions [9].

It is postulated that these closed-loop control systems allow to compensate for detrimental effects like wear or coking by maintaining injection rate and quantities over engine lifetime [10][11]. The German Research Foundation has funded a project at Technical University of Munich to investigate the influence of these alterations like wear and coking onto critical parameters as the injection rate and eventually the engine-out emissions. The key goal is to find parameters related to the deterioration of the injection rate and to develop an open-loop control that enables to restore the desired injection parameters. The model approach for the identification of these aging effects is presented in [13].

\section{Experimental Setup}

The measurement setup consists of a third generation common rail diesel injector that is equipped with multiple sensors. A solenoid valve in the upper part regulates the start and end of injection by opening and closing the discharge throttle of the control volume. When the solenoid is energized, diesel flows out of the control volume through the discharge throttle and less fuel is flowing in through the inlet throttle, which possesses a smaller diameter. Hence, fluid pressure inside the control volume decreases. The upward force generated by the rail pressure on the annular upper part of the nozzle needle exceeds the downward force of the control volume pressure, which is acting on the top area of the control piston. This difference in forces leads to the lift of the needle, which in turn drives the control piston. When the energizing of the solenoid ends, the downward force of the control volume pressure together with the nozzle spring force surpasses the nozzle sac pressure force. The nozzle subsequently closes and injection ends.

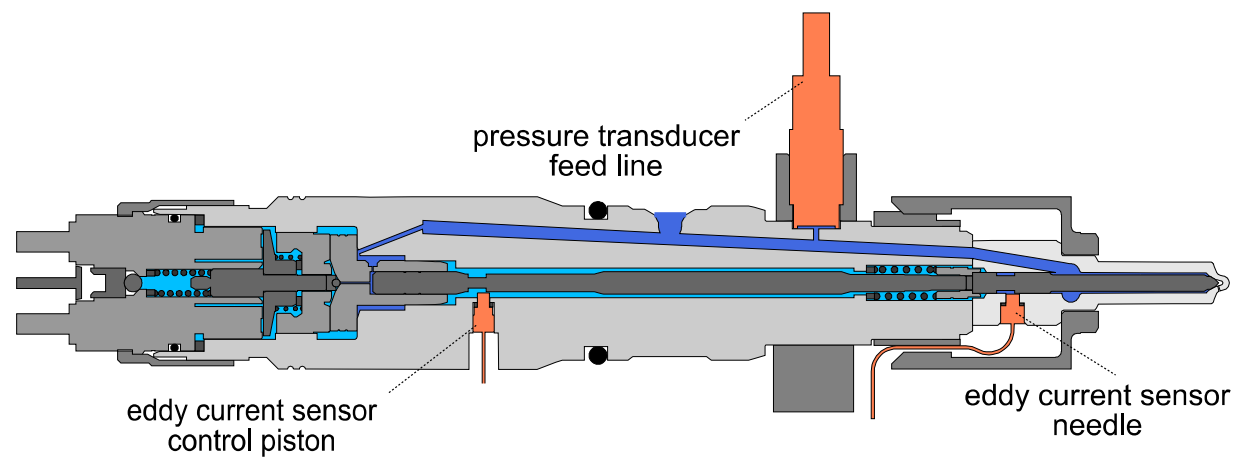

Figure 1. Schematic sensor setup of the modified solenoid injector (note: some sensors and lines are projected to the section plane for clarity)

For the measurement of needle or control piston motion measurement principles like opto-electronical sensors have been presented [14]. Furthermore, a solution to detect needle opening and closing by employing an electric circuit, which is closed by the needle in its extreme positions, has been introduced [15]. Nevertheless, as they prove high robustness and a high signal-to-noise ratio, two eddy current sensors are utilized to measure the motions of control piston and needle, respectively. A piezo-resistive pressure transducer gauges the fuel pressure inside the feed line of the injector (see Figure 1). The sensors are mounted in different parts of the injector for measuring independent parameters. These parameters in turn are the basis for the development of an open-loop control compensating for alterations of injection behavior caused by aging effects.

The linear measurement range of the eddy current sensors of $0.5 \mathrm{~mm}$ is not significantly larger than the lift of both control piston and needle with $0.35 \mathrm{~mm}$ and previous measurements showed an overlay of control piston motion and its deformation caused by fluid pressure. To clarify the extent of this deformation those two components are simulated using the finite element method.

The simulation model uses a force (D) to represent the diesel fluid acting downward on top of the control piston with rail pressure. The upper part of the piston that is guided in the control volume unit is represented by a frictionless support (B). All inside faces of the nozzle are pressurized with rail pressure $(E)$ while the ring-shaped outside face serves as a fixed support (A). The needle is guided frictionless inside the nozzle $(F)$ and the needle spring force (C) acts on top of the needle (see Figure 2). 
Simulation results show that outfitting both control piston and needle with circular grooves does not have a significant effect on their deformation compared to their unaltered counterparts in the production injector (see Figure 2). These grooves are necessary for the measuring principle of the eddy current sensor. The simulation proves that the stiffness properties of the two moving parts remain unchanged, thus the injection process is left uninfluenced. As the static deformation is barely greater than the difference between linear measurement range of the eddy current sensor and the operational lift of the control piston (for the needle it is considerably smaller), the eddy current sensors are able to measure both deformation and lift of control piston and needle in the linear measurement range.
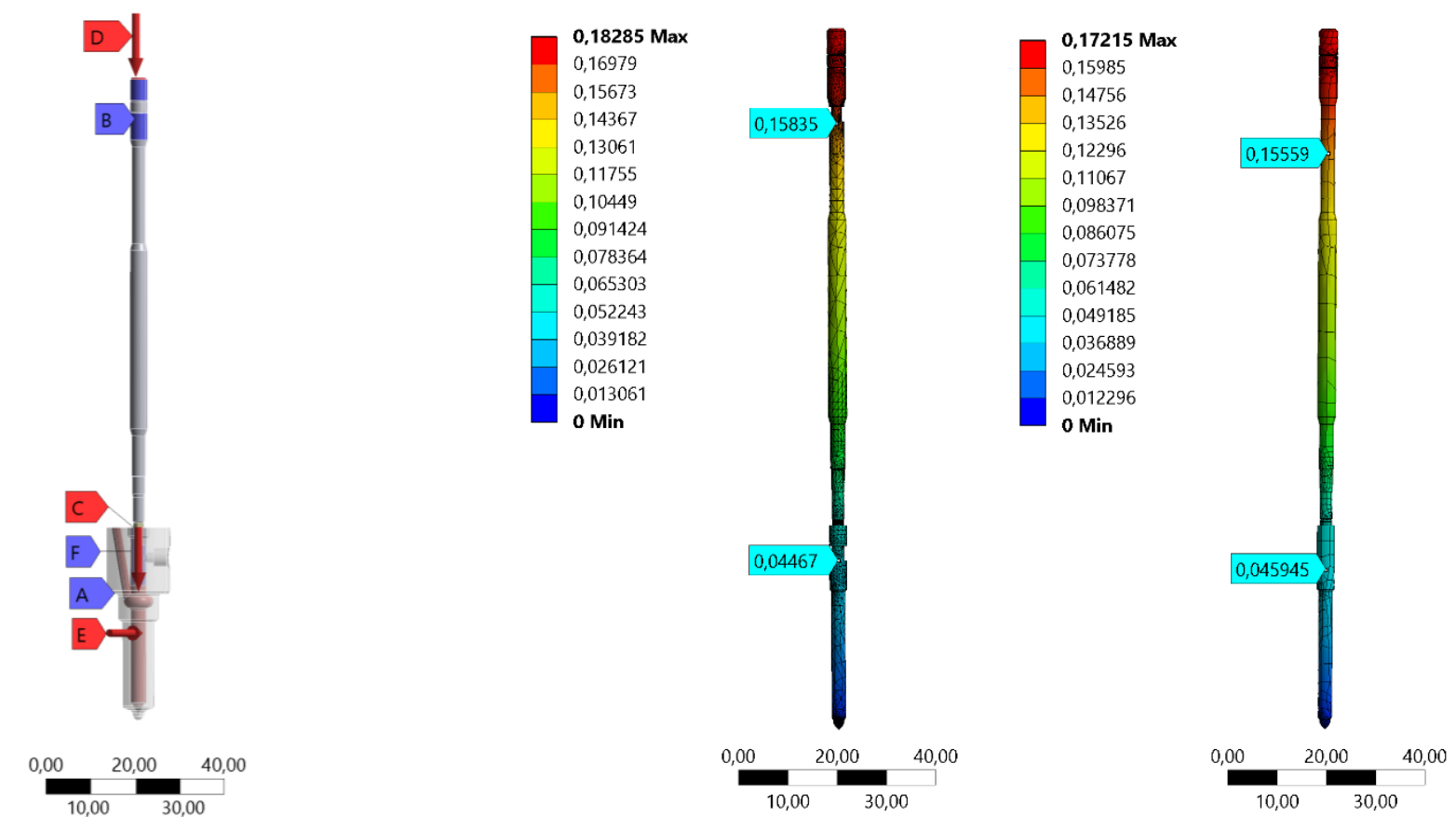

Figure 2. Comparison of needle $\boldsymbol{x}_{N}$ and control piston $\boldsymbol{x}_{C p}$ deformations due to rail pressure $\boldsymbol{p}_{\text {Railset }}=180 \mathrm{MPa}$ (left: boundary conditions of finite element simulation; middle: needle and control piston for lift measurements; right: unaltered needle and control piston)

A custom software is used for the data acquisition and the processing of measurement data. The analysis steps are shown in Table 1. The injection rate $\dot{m}$ is derived from measuring the dynamic pressure in the fuel-filled coiled tube using a piezoelectric pressure transducer. Because of this measurement principle, the signal undergoes a drift compensation, a filtering process and a subsequent conversion to a mass-flow using the cross-section of the tube, the speed of sound and the density of diesel (compare [16]).

Table 1. Data processing steps applied to measurement parameters

\begin{tabular}{|c|c|c|c|c|}
\hline Data processing & 1. & 2. & 3. & 4. \\
\hline Parameter & $\begin{array}{l}\text { Drift } \\
\text { compensation }\end{array}$ & Filtering & Conversion & Averaging \\
\hline Injection rate $\dot{m}$ & $\bullet$ & $\bullet$ & $\mathrm{V}$ to $\mathrm{mg} / \mathrm{ms}$ & $\bullet$ \\
\hline Injector inside pressure $p_{I n j}$ & - & $\bullet$ & $\mathrm{V}$ to $\mathrm{MPa}$ & $\bullet$ \\
\hline Measured rail pressure $p_{\text {Rail,mea }}$ & - & $\bullet$ & $\mathrm{V}$ to $\mathrm{MPa}$ & $\bullet$ \\
\hline Control piston lift $x_{C p}$ & - & $\bullet$ & $\mathrm{V}$ to $\mathrm{mm}$ & $\bullet$ \\
\hline Needle lift $x_{N}$ & - & $\bullet$ & $V$ to $\mathrm{mm}$ & $\bullet$ \\
\hline
\end{tabular}

All measurements in this paper are performed while measuring the injection rate utilizing a purpose-built injection rate analyzer applying the Bosch working principle [16]. The fuel supply system for the common rail injector consists of a commercial high-pressure system with low-pressure pump, high-pressure pump with suction valve and common rail. Figure 3 outlines the experimental setup and the most import measurement parameters. 
All other signals are filtered likewise with a second order Butterworth filter to reduce high-frequent noise and are converted from current or voltage signal into their physically correct dimension. Generally every signal is averaged using multiple (here: five) single measurements in order to avoid statistically distributed deviating signals.

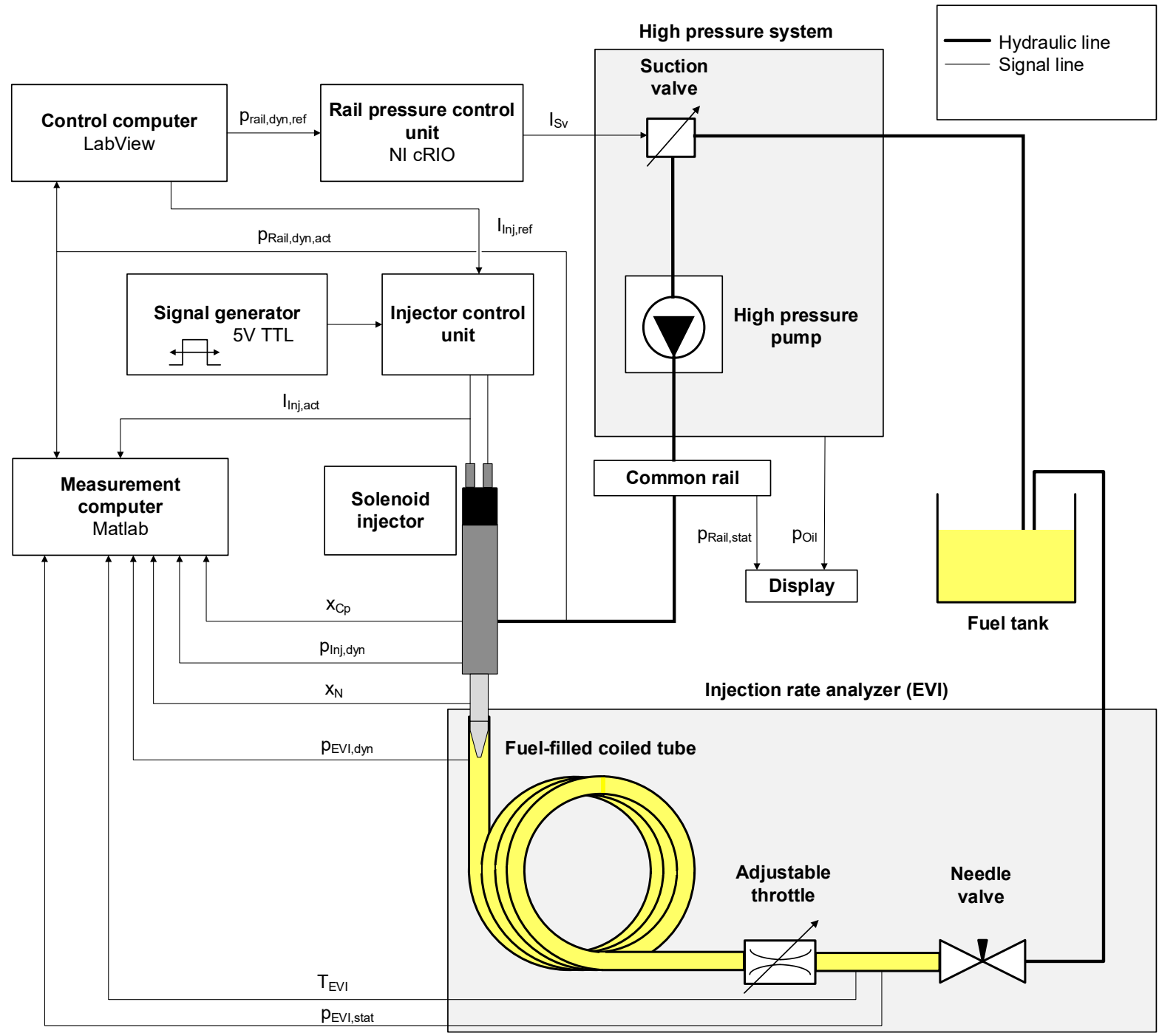

Figure 3. Schematic overview of measurement setup and main parameters

\section{Measurement Results}

Although the motion of the nozzle needle regulates the fluid flow from feed line to nozzle sac, it is neglected in this study. The implementation of the eddy current sensor for measuring control piston motion leaves the external geometry of the injector body unaltered. The nozzle with the applied eddy current sensor changes the external geometry of the injector as it necessitates a different union nut. This union nut is to make room for the minimum bending radius of the wire of the eddy current sensor. In the future, engine investigations will be performed with the developed injector and different nozzles. Under the premise of using the existing cylinder head, no major change in the external geometry of the injector is admissible. Thus, the main aim of the presented investigations is to clarify correlations of control piston motion and fuel pressure at two distinct positions to key injection parameters.

Figure 4 illustrates the measured injection rates for four different set rail pressures. Higher rail pressures cause a steeper increase and an earlier decrease of injection rate while at the same time a rise in maximum injection rate is observed.

The reason for this behavior is the increase in nozzle sac pressure that exerts a higher upward force on the needle. This causes a faster acceleration of the needle and a faster increase of the hydraulic flow area between needle seat and nozzle tip. Ultimately, a higher injection rate results for higher rail pressures at the same instant of time in 
the opening phase of the nozzle needle. The same but inverse causal relationship applies to the closing phase of the needle.

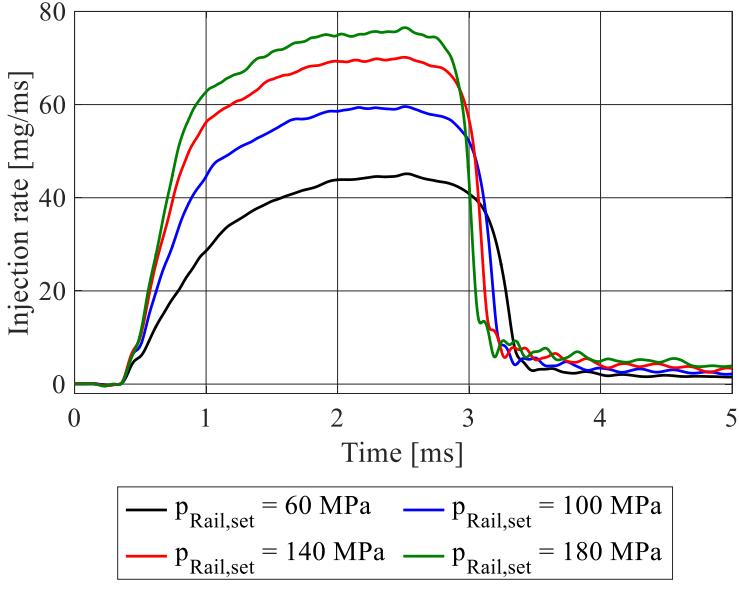

Figure 4. Injection rate profiles of the modified common rail injector utilized for control piston and needle lift measurements $\left(t_{E T}=2.2 \mathrm{~ms}\right)$

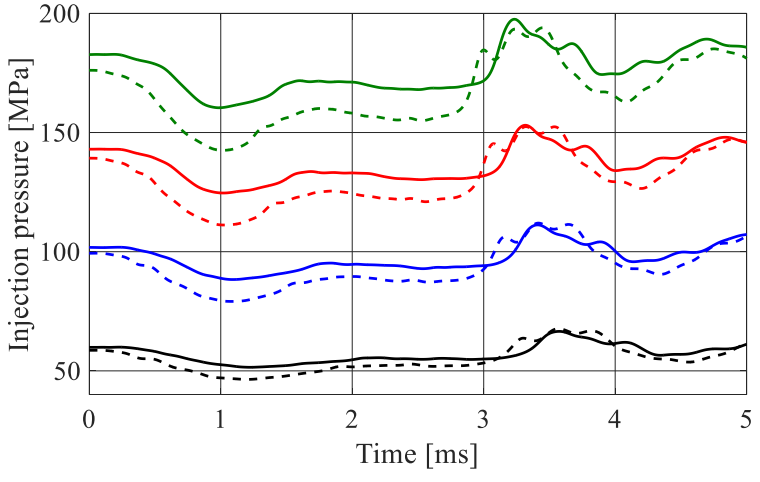

$$
\begin{aligned}
& -\mathrm{p}_{\text {Rail,set }}=60 \mathrm{MPa}-\mathrm{p}_{\text {Rail,set }}=100 \mathrm{MPa} \\
& -\mathrm{p}_{\text {Rail,set }}=140 \mathrm{MPa}-\mathrm{p}_{\text {Rail,set }}=180 \mathrm{MPa}
\end{aligned}
$$

Figure 5. Pressure inside feed line $p_{\text {Inj }}$ (dashed lines) and before inlet connector $p_{\text {Rail,act }}$ (solid lines) $\left(t_{E T}=2.2 \mathrm{~ms}\right.$ )

The maximum injection rate is a function of the difference of common rail pressure and backpressure inside of the injection rate analyzer (see Equation (1) according to [17]). Therefore, it increases with higher common rail pressures as the backpressure is kept constant for all investigations.

$$
\dot{m}=C_{d} \cdot A_{h} \cdot \rho_{f} \cdot \sqrt{\frac{2 \cdot\left(p_{\text {Rail,mea }}-p_{E V I, \text { dyn }}\right)}{\rho_{f}}}
$$

Various studies have demonstrated the feasibility of detecting injection events by analyzing the rail pressure trace [9]. It has also been proven that by subjecting the rail pressure signal to a short-time Fourier analysis, it is possible to discriminate between pilot and main injection as well as to detect injector malfunction [18]. Therefore, both pressure before inlet connector and pressure inside the feed line are evaluated.

The comparison of pressure before the inlet connector and in the feed-line of the injector shows an overlap of both pressures between $3.2 \mathrm{~ms}$ and $3.6 \mathrm{~ms}$. Here the pressure in the feed line reaches the level of the pressure before the inlet connector or even slightly surpasses its level (see Figure 5). The temporal concurrence of the peaks of both measured pressures demonstrates a correlation to the end of injection.

At the end of injection a pressure wave is generated by the closing needle [19]. This pressure wave propagates from the needle seat upstream through feed line and inlet connector. Thus, a local maximum is detectable first in the signal of the pressure transducer in the feed line and only afterwards at the sensor before the inlet connector. When evaluating the temporal difference between these first local maxima on feed line pressure and pressure before inlet connector, a distance of around $400 \mathrm{~mm}$ between the two pressure transducers is calculated (see Table 5 lists the data for the calculation of the distance between the two pressure sensors.

Table 5 in Annex). This is in good agreement with the actual distance between the sensors and supports the thesis of the wave propagation as the cause for the local pressure peaks on both signals.

The difference between the first minimum of the injection rate (used here as end of injection) and the coinciding pressure peaks is in the magnitude of under $100 \mu \mathrm{s}$, while the temporal deviation of the concurrence of pressures peak with regard to the end of injection is under $3 \%$ for rail pressures between 60 and 180 MPa (see Table 2). Higher set rail pressures show a smaller discrepancy between end of injection and concurrence of pressures peak. This temporal accuracy of detecting the end of injection by indirect means is remarkably higher than the one of a different approach, which determines the end of injection by detecting and evaluating the sound-borne noise in engine parts utilizing knock sensors [20].

Furthermore, a method to detect start and end of injection by assessing the derivative of the common rail pressures signal has been presented [19]. The here presented method by regarding the concurrence of the pressure peaks of the two sensors as a detection of end of injection is more precise than that method. Table 2 presents the difference between the maximum derivative of the pressure before the inlet connector, which is only more accurate for a set rail pressure of $60 \mathrm{MPa}$. 
Table 2. Assessment of correlation between injection rate and pressure inside feed line $\left(\boldsymbol{t}_{E T}=2.2 \mathrm{~ms}\right)$

\begin{tabular}{|c|c|c|c|c|c|c|c|}
\hline $\begin{array}{l}\text { Set rail } \\
\text { pressure } \\
p_{\text {Rail,set }} \\
\text { [MPa] }\end{array}$ & $\begin{array}{l}\text { 1. Minimum } \\
\text { of control } \\
\text { piston lift } \\
t_{M c p} \\
\text { [ms] }\end{array}$ & $\begin{array}{l}\text { 1. Minimum } \\
\text { of injection } \\
\text { rate } t_{\text {Mir }} \\
\text { [ms] }\end{array}$ & $\begin{array}{l}\text { Concur- } \\
\text { rence of } \\
\text { pressure } \\
\text { peaks } t_{C p p} \\
\text { [ms] }\end{array}$ & $\begin{array}{l}\text { Difference } \\
t_{D i f 1}= \\
t_{C p p}-t_{M i r} \\
{[\mathrm{~ms}]}\end{array}$ & $\begin{array}{l}\text { Deviation } \\
t_{\text {Dev }}= \\
t_{D i f} / t_{D i} \\
{[\%]}\end{array}$ & $\begin{array}{l}\text { Max. derivative } \\
\text { of pressure } \\
\text { before inlet } \\
\text { connector } \\
t_{M d p} \\
{[\%]}\end{array}$ & $\begin{array}{l}\text { Difference } \\
t_{D i f 2}= \\
t_{M d p}-t_{M i r} \\
{[\mathrm{~ms}]}\end{array}$ \\
\hline 60 & 3.448 & 3.485 & 3.568 & 0.083 & 2.64 & 3.432 & -0.053 \\
\hline 100 & 3.323 & 3.350 & 3.415 & 0.065 & 2.17 & 3.285 & -0.065 \\
\hline 140 & 3.245 & 3.273 & 3.323 & 0.050 & 1.71 & 3.192 & -0.081 \\
\hline 180 & 3.175 & 3.195 & 3.240 & 0.045 & 1.58 & 3.112 & -0.083 \\
\hline
\end{tabular}

Figure 6 shows that the gradient in control piston upward motion is considerably steeper for higher set rail pressures. Thus, the maximum lift is attained earlier and maintained for a longer period of time. The comparison of control piston motions with another investigation [21], in which an eddy current sensor is utilized, reveals a remarkable difference as in this study there is no change in gradient in the upward motion (see Figure 7).

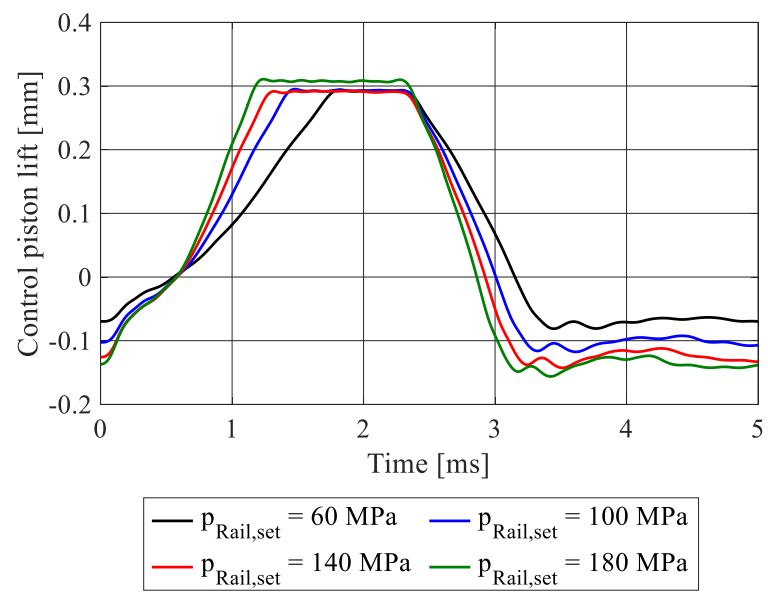

Figure 6. Control piston lifts with varied set rail pressures $p_{\text {Rail,set }}\left(t_{E T}=2.2 \mathrm{~ms}\right)$

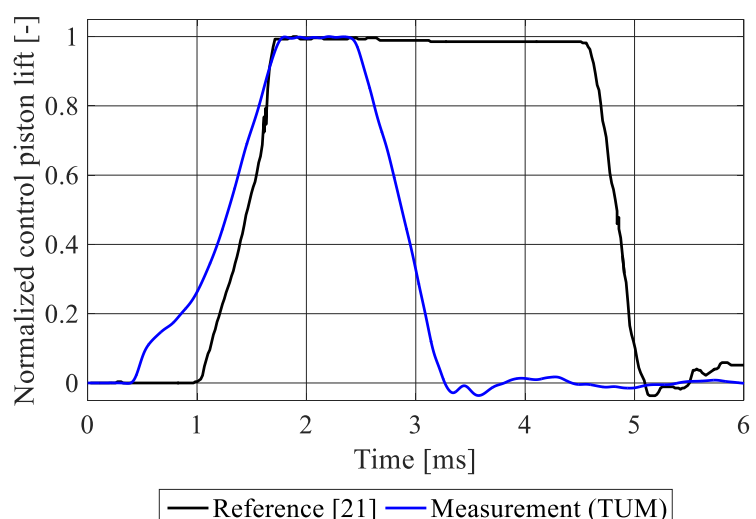

Figure 7. Comparison of control piston lift of reference [21] and measured control piston lift ( $p_{\text {Rail,set }}=140 \mathrm{MPa}, t_{E T, T U M}$ $\left.=2.2 \mathrm{~ms}, t_{E T,[21]}=2.0 \mathrm{~ms}\right)$

The temporal starting point for the descent of the control piston is identical for every set rail pressure while the gradient of the downward motion is again depending on the set rail pressure. The changing gradient in the rising motion is noteworthy, as it points to the elastic behavior of the steel control piston. After energizing the solenoid valve the pressure in the control volume decreases what leads to a lower downward force on top of the control piston and a reduction of the elastic deformation. The elongation of the control piston overlays with the upward motion of the piston in the ballistic stage of the injection process and causes the change of gradient. This observation is in accordance with control piston behavior in one-dimensional hydraulic injector simulations.

Table 3. Comparison of simulated and measured elastic deformation of the control piston due to applied rail pressure and closed solenoid valve

\begin{tabular}{|c|c|c|c|c|}
\hline $\begin{array}{l}\text { Set rail pressure } \\
p_{\text {rail,set }} \\
\text { [MPa] }\end{array}$ & $\begin{array}{l}\text { Simulated control } \\
\text { piston lift } x_{c p, s}[\mathrm{~mm}]\end{array}$ & $\begin{array}{l}\text { Measured control } \\
\text { piston lift } x_{c p, m}[\mathrm{~mm}]\end{array}$ & $\begin{array}{l}\text { Difference } D_{c p a}= \\
x_{c p, m}-x_{c p, s} \\
{[\mathrm{~mm}]}\end{array}$ & $\begin{array}{l}\text { Deviation } D_{c p r}= \\
D_{c p a} / x_{c p, m} \\
{[\%]}\end{array}$ \\
\hline 60 & -0.0533 & -0.0696 & -0.0163 & 23.4 \\
\hline 100 & -0.0882 & -0.1026 & -0.0144 & 14.0 \\
\hline 140 & -0.1235 & -0.1258 & -0.0023 & 1.8 \\
\hline 180 & -0.1585 & -0.1371 & -0.0214 & 15.6 \\
\hline
\end{tabular}


The comparison of measured (lift at $t_{E T}=0 \mathrm{~ms}$ in Figure 6) and simulated elastic deformation (see paragraph Experimental Setup) illustrates a strong congruence in terms of magnitude (see Table 3). One possible reason for the deviation of measured control piston deformation is the non-linearity of the controller of the eddy current sensor at the end of its linear measuring range. As the nozzle needle is significantly shorter than the control piston of the investigated injector, elastic deformation exerts a minor influence on its motion and the findings of the control piston motion are not transferrable to needle motion.

\section{Conclusions}

A common rail injector was equipped with two eddy current sensors and a piezoelectric pressure transducer. This novel setup allowed to measure control piston and needle motion along with injector inside pressure simultaneously for the first time.

Finite elements simulations proved that the geometrical alterations of control piston and needle did not affect their mechanical behavior. Moreover, these simulations clarified the magnitude of their deformation due to fluid pressure in the control volume and confirmed the measured initial deformation of these two parts.

A concurrence of local maxima of pressure before the inlet connector and pressure in the feed line of the injector occurred in close temporal vicinity to the end of injection. The measurement results showed that the gradient of control piston upward motion changes as the control piston is lifted due to the decrease of its elastic deformation. This non-linear motion of the control piston was different to the linear motion in a similar study, but was supported by a one-dimensional hydraulic simulation of the injector.

In general measuring the control piston motion of a common rail diesel injector with an eddy current sensor exhibited a low level of noise on the raw signal and proved a very high repeatability (see Figure 8 and Figure 9 in Annex). Additionally no detrimental electromagnetic influence of the energization of the solenoid valve on the raw signal was detectable as asserted in a previous study [14].

In summary, the presented sensor arrangement exhibited a high temporal accuracy and an ability to detect small differences in the measured parameters. It is suited for detecting aging effects if these alterations affect the control piston motion and the injector inside pressure. Therefore, these two parameters are an appropriate basis for the development of an open-loop control strategy countering diesel injector aging. Furthermore, the measured control piston lifts are a validation basis for hydraulic injector simulations and the concurrence of local pressure maxima is useful as indirect means to detect the end of injection in future investigations.

\section{Acknowledgements}

The authors thank the German Research Foundation DFG for the funding of the project (reference number WA 2468/4-1) in which the here presented results originated. Furthermore, the authors thank Martin Niedermeier for the development the injector and Mario Meinhardt for the development of the data acquisition.

\section{Nomenclature}

$\begin{array}{lll}\text { Symbol } & \text { Unit } & \text { Measured parameter } \\ A_{h} & \mathrm{~m}^{2} & \text { Total cross-section of nozzle holes } \\ C_{d} & - & \text { Discharge coefficient of nozzle hole } \\ I_{\text {Inj,ref }} & \mathrm{A} & \text { Reference injector current } \\ I_{\text {Inj,mea }} & \mathrm{A} & \text { Measured injector current } \\ I_{\text {Sv }} & \mathrm{A} & \text { Suction valve current } \\ k & - & \text { Conicity factor } \\ \dot{m} & \mathrm{mg} / \mathrm{ms} & \text { Injection rate } \\ p_{\text {EVI,dyn }} & \mathrm{MPa} & \text { Dynamic pressure injection rate analyzer } \\ p_{\text {EVI,stat }} & \mathrm{MPa} & \text { Static pressure injection rate analyzer } \\ p_{\text {Inj }} & \mathrm{MPa} & \text { Pressure inside feed line of injector } \\ p_{\text {Oil }} & \mathrm{MPa} & \text { Oil pressure inside gear box } \\ p_{\text {Rail,mea }} & \mathrm{MPa} & \text { Measured rail pressure } \\ p_{\text {Rail,set }} & \mathrm{MPa} & \text { Set rail pressure } \\ p_{\text {Rail,stat }} & \mathrm{MPa} & \text { Static rail pressure } \\ t_{\text {Dif } 1} & \mathrm{~ms} & \text { Difference between } t_{C p p} \text { and } t_{\text {Mir }} \\ t_{\text {Dif } 2} & \mathrm{~ms} & \text { Difference between } t_{M d p} \text { and } t_{M i r} \\ t_{E T} & \mathrm{~ms} & \text { Energizing time } \\ t_{C p p} & \mathrm{~ms} & \text { Concurrence of pressure peaks } \\ t_{M c p} & \mathrm{~ms} & \text { First minimum of control piston lift } \\ & & \end{array}$




$\begin{array}{lll}t_{M d p} & \mathrm{~ms} & \text { Maximum derivative of pressure before inlet connector } \\ t_{M i r} & \mathrm{~ms} & \text { First minimum of injection rate } \\ T_{E V I} & \mathrm{~K} & \text { Fuel temperature injection rate analyzer } \\ x_{C p} & \mathrm{~mm} & \text { Control piston lift } \\ x_{N} & \mathrm{~mm} & \text { Needle lift } \\ \rho_{f} & \mathrm{~ms} & \text { Fuel density }\end{array}$

\section{References}

[1] Galante-Fox, J., and Bennett, J., Diesel injector internal deposits in High Pressure Common Rail diesel engines, Conference Fuel Systems for IC Engines, London, 2012, doi:10.1533/9780857096043.5.157

[2] Fink, C., Crusius, S., Junk, R., Schümann, U. et al., Fuel-related Deposits in Common-Rail Injectors, $24^{\text {th }}$ Aachen Colloquium Automobile and Engine Technology, 2015

[3] d'Ambrosio, S., and Ferrari, A., Diesel Injector Coking: Optical-Chemical Analysis of Deposits and Influence on Injected Flow-Rate, Fuel Spray and Engine Performance, Journal of Engineering for Gas Turbines and Power 134(6): 062801, 2012, doi:10.1115/1.4005991

[4] Winterbone, D., Clough, E., Rao, K., Richards, P. et al., The Effect of DI Nozzle Fouling on Fuel Spray Characteristics, SAE Technical Paper 922232, 1992, doi:10.4271/922232

[5] Williams, R., Smith, A., and Buttery, I., Formation and Removal of Injector Nozzle Deposits in Modern Diesel Cars, SAE International Journal of Fuels and Lubricants 6(1):230-240, 2013, doi:10.4271/2013-01-1684

[6] Ikemoto, M., Omae, K., Nakai, K., Ueda, R. et al., Injection Nozzle Coking Mechanism in Common-rail Diesel Engine, SAE Technical Paper 2011-01-1818, 2011, doi:10.4271/2011-01-1818

[7] Tang, J., Pischinger, S., Lamping, M., Körfer, M. et al., Coking Phenomena in Nozzle Orifices of DI-Diesel Engines, SAE Technical Paper 2009-01-0837, 2009

[8] Ullrich, J., Steininger, R., Semisch, R., and Reke, M., New Methodology for Early Injector Qualification in Real Engine, $10^{\text {th }}$ Conference Diesel and Gasoline Direct Injection, Berlin, 2016

[9] Miyaki, M., Takeuchi, K., Ishizuka K., and Sasaki, S., The Breakthrough of Common Rail System: Closed-loop Control Strategy Using Injector with Built-in Pressure Sensor, 30. Internationales Wiener Motorensymposium, Vienna, 2009

[10] Miyaura, T., Morikawa, A., Ito, Y., Ishizuka, K. et al., Development of Diesel Engine using New Fuel Injection System - Direct Monitoring of Fuel Injection Pressure using Injector with Built-in Sensor, and its Applications, SAE Technical Paper 2013-01-1739, 2013

[11] Marker, J., Willmann, M., Mlicki, F., Mehr, A. et al., Potential of INSITU closed-loop control of fuel injection in large LFO engines, $15^{\text {th }}$ Conference The Working Process of the Internal Combustion Engine, Graz, 2015

[12] Schöppe, D., Stahl, C., Krüger, G., and Dian, V., Servogetriebene Piezo-Common-Rail-Dieseleinspritzung, Motortechnische Zeitschrift 73(3):208-213, 2012, doi:10.1365/s35146-012-0266-9

[13] Hofmann, O., Strauß, P., Schuckert, S., Huber, B. et al., Identification of Aging Effects in Common Rail Diesel Injectors Using Geometric Classifiers and Neural Networks, SAE Technical Paper 2016-01-0813, 2016, doi:10.4271/2016-01-0813

[14] Coppo, M., Dongiovanni, C., and Negri, C., A Linear optical sensor for measuring needle displacement in common-rail diesel injectors, Sensors and Actuators A 134(2):366-373, 2007, doi:10.1016/j.sna.2006.05.038

[15] Voigt, P., Schiffgens, H.-F., Béduneau, J.-L., Cochet, T. et al., Delphi Injector Closed Loop Control Strategy Using the "Switch" Technology for Diesel Passenger Cars, 25th Aachen Colloquium Automobile and Engine Technology, Aachen, 2016

[16] Bosch, W., Der Einspritzgesetz-Indikator, ein neues Meßgerät zur direkten Bestimmung des Einspritzgesetzes von Einzeleinspritzungen, Motortechnische Zeitschrift 25(7):268-282, 1964

[17] Payri, R., Gimeno, J., Novella, R., and Bracho, G., On the rate of injection modeling applied to direct injection compression engines, International Journal of Engine Research 17(10):1015-1030, 2016, doi:10.1177/1468087416636281

[18] Payri, R., Lujan, J. M., Guardiola, C., and Rizzoni, G., Injection diagnosis through common-rail pressure measurement, Proceedings of the Institution of Mechanical Engineers, Part D: Journal of Automobile Engineering 220(3):347-357, 2006, doi:10.1243/09544070JAUTO34

[19] Delphi International Operations Luxembourg S.À.R.L., Novel Fuel Rail for Injection System, Patent Application WO 2017/025348 A1, 2017

[20] Christ, K., Kalibrierung von Magnet-Injektoren für Benzin-Direkteinspritzsysteme mittels Körperschall, Ph.D. thesis, Karlsruhe Institute of Technology, 2011

[21] Seykens, X.L.J., Somers, L.M.T., and Baert, R.S.G., Detailed Modeling of Common Rail Fuel Injection Process, Journal of Middle European Construction and Design of Cars 3(2-3):30-39, 2005 


\section{Annex}

In Figure 8 and Figure 9 five consecutive control piston lift are depicted. A low level of noise on the lift curves is clearly visible.

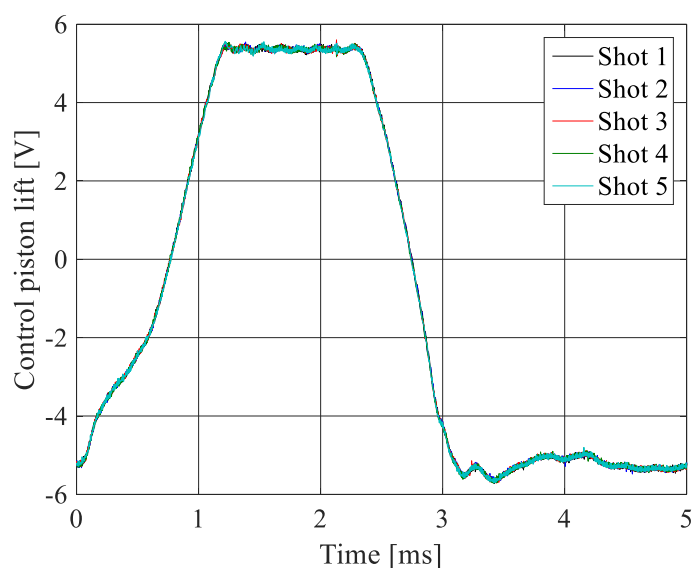

Figure 8. Raw data of five single control piston motion measurements $\left(p_{\text {Rail,set }}=180 \mathrm{MPa}, t_{E T}=2.2 \mathrm{~ms}\right.$ )

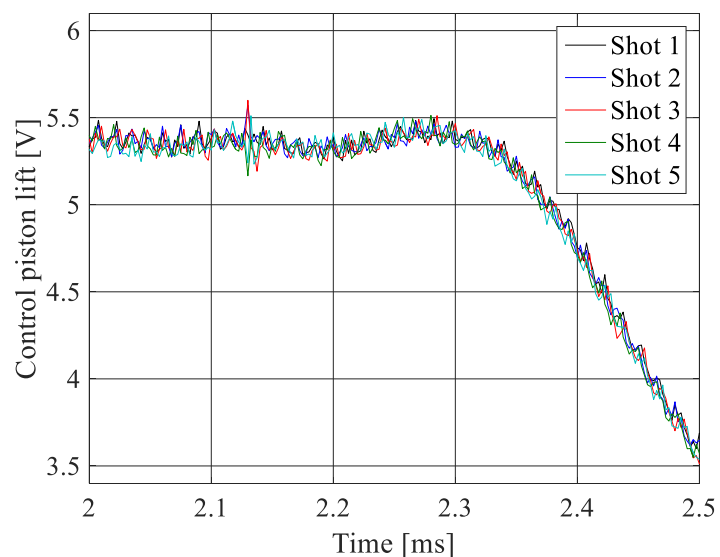

Figure 9. Illustration of noise level of raw signal of control piston motion (magnification of Figure 8)

Table 4 summarizes the key properties of the injector and of its production nozzle that are utilized for the here presented investigations.

Table 4. Parameters of nozzle and injector

\begin{tabular}{|l|l|}
\hline \multicolumn{2}{|l|}{ Injector } \\
\hline Type & $\begin{array}{l}\text { Commercial third generation } \\
\text { common rail }\end{array}$ \\
\hline Rail pressure & $180 \mathrm{MPa}$ \\
\hline Nozzle & Sac \\
\hline Type & 1.5 \\
\hline Conicity factor $k$ & $0.177 \mathrm{~mm}$ \\
\hline Spray hole diameter & 0.87 \\
\hline Discharge coefficient $C_{d}$ &
\end{tabular}

Table 5 lists the data for the calculation of the distance between the two pressure sensors.

Table 5. Evaluation of pressure data

\begin{tabular}{|l|l|l|l|l|l|l|}
\hline $\begin{array}{l}\text { 1. Maximum } \\
\text { pressure feed line } \\
{[\mathbf{m s}]}\end{array}$ & $\begin{array}{l}\text { 1. Maximum } \\
\text { pressure before inlet } \\
\text { connector [ms] }\end{array}$ & Difference [ms] & $\begin{array}{l}\text { Bulk modulus } \\
{\left[\mathbf{N} / \mathbf{m m}^{2}\right]}\end{array}$ & $\begin{array}{l}\text { Density } \\
{\left[\mathbf{k g}^{3} \mathbf{m}^{3}\right]}\end{array}$ & $\begin{array}{l}\text { Speed of } \\
\text { sound }[\mathrm{m} / \mathbf{s}]\end{array}$ & $\begin{array}{l}\text { Length } \\
{[\mathrm{m}]}\end{array}$ \\
\hline 3,305 & 3,567 & 0,262 & 1738 & 840 & 1438 & 0,377 \\
\hline 3,152 & 3,395 & 0,243 & 2155 & 857 & 1585 & 0,385 \\
\hline 3,070 & 3,315 & 0,245 & 2567 & 871 & 1716 & 0,421 \\
\hline 3,000 & 3,225 & 0,225 & 2961 & 884 & 1830 & 0,412 \\
\hline
\end{tabular}

